\title{
Escrita de si e memória: a narrativa como testemunho de vidas
}

\section{Self-writing and memory: narrative as a testimony of lives}

\author{
Josimere Maria da Silva ${ }^{1}$ \\ Hudson Marques da Silva²
}

\begin{abstract}
Resumo: Este ensaio propõe uma discussão em torno dos conceitos de "memória", "escrita de si" e "literatura de testemunho" numa tentativa de pensar seu papel na construção de um texto em que o sujeito narra a sua própria história. Para isso, tomam-se como exemplos duas obras da literatura latino-americana: Margem das Lembranças, romance escrito na década de 1960, pelo escritor pernambucano Hermilo Borba Filho, e Paula, da escritora chilena Isabel Allende, com datação de três décadas depois. Em comum, estas obras de caráter autobiográfico trazem em suas superfícies a reconstrução em tom memorialístico das vidas de seus autores através de uma narrativa em primeira pessoa: a obra hermiliana nos apresentando um sujeito que busca, antes de tudo, uma compreensão de si mesmo a partir de seu próprio testemunho e a narrativa de Allende expondo o desespero de uma mãe que acredita inutilmente que, ao contar sua trajetória, estará aproximando da vida uma filha que já se encontra em coma profundo e irreversível. Assim, tenta-se compreender como a recorrência à memória contribui para a construção de uma escrita de si nos textos ora citados e também de que modo esse tipo de escrita dá conta de dizer o sujeito que testemunha sua vida.
\end{abstract}

Palavras-chave: Escrita de si; Memória; Literatura de testemunho; Isabel Allende; Hermilo Borba Filho.

Abstract: This paper proposes an overview on concepts of memory, self-writing and testimonial literature to reflect on their roles in the construction of texts in which the subject narrates their own history. For that, two Latin American works are taken as examples: Margem das Lembranças, novel written in the 1960s by Hermilo Borba Filho, a writer from Pernambuco, Brazil, and Paula, novel by the Chilean writer Isabel Allende, written three decades later. Both the works are similar for their autobiographical features and for presenting memorialistically a reconstruction of their authors' life by a first person narrative: the Hermilian novel shows a subject who seeks above all to comprehending himself starting from their own testimony, and Allende's narrative, in turn, exposes a mother's despair, who vainly believes that by telling her path would be getting closer to a daughter who already is in deep and irreversible coma. Thus it debates how resorting to memory can contribute to elaborating a self-writing considering the mentioned texts, and also how this kind of writing can represent the subject who bears witness of their life.

Keywords: Self-writing; Memory; Testimonial literature; Isabel Allende; Hermilo Borba Filho.

\footnotetext{
1 Doutoranda em Literatura e Interculturalidade pela Universidade Estadual da Paraíba. Professora do Instituto Federal de Educação, Ciência e Tecnologia de Alagoas. Email: josimaria.Il@gmail.com

2 Doutor em Literatura e Interculturalidade pela Universidade Estadual da Paraíba. Professor do Instituto Federal de Educação, Ciência e Tecnologia de Pernambuco. Email: marqueshudson@hotmail.com
} 


\section{Introdução}

O século XIX traz consigo o grande boom das biografias e autobiografias (GOMES, 2004), o que implica dizer que o sujeito de então encontrou nas narrativas em primeira pessoa um meio de solidificar sua história. Ao narrar-se, esse sujeito materializa em um livro seu passado de outrora, aproximando de si acontecimentos antes vividos e que sua memória permite-lhe reconstituir. Ao tomar a atitude de narrar-se, portanto, esse sujeito se refaz, reconstrói-se por intermédio de seu próprio testemunho.

É esse narrar a si próprio que Gomes (2004) denomina "escrita de si", segundo ela, uma prática que tem início já no século XVIII, "[...] quando indivíduos comuns passaram a produzir, deliberadamente, uma memória de si" (GOMES, 2004, p. 10-11). Esse processo consolida-se no século XIX, quando aparece na literatura o denominado "romance moderno" a partir do qual se pode chegar à denominação da escrita de si, visto que ela nos apresenta um sujeito a dizer-se, o sujeito cartesiano, seguindo Foucault (2006), aquele que se volta para si, que se preocupa consigo mesmo.

Uma particularidade da escrita de si estaria no fato de que, nela, o sujeito mantém estreita relação com o seu passado. Tanto no romance Margem das Lembranças como em Paula, identificam-se histórias ambientadas no passado daqueles que ali se dizem. Ambos os narradores recorrem à memória numa tentativa de trazer ao presente o curso de suas vidas passadas. Assim, o espaço da narrativa é aquele em que os autores estiveram outrora, vivendo os acontecimentos mais corriqueiros e os mais determinantes, inseridos numa esfera em que se mantinham numa espécie de inconsciência de sua condição, recobrada agora, no momento em que se torna possível reconstruir tais eventos.

No caso de Margem das Lembranças, existe um narrador que retorna à sua juventude e tenta revisitar suas vivências numa pequena cidade do interior de Pernambuco. Assim, suas descobertas sexuais, o primeiro emprego, o contato com a impunidade, a prostituição, o crime, o vício e, mais tarde, o envolvimento com a política, a prisão e as torturas são eventos evocados no plano da narrativa mediante a qual Hermilo reconstrói sua história. Ele que se propõe a colocar-se "na balança", ele de um lado, sua vida de outro. É relembrando o passado que o narrador descobre uma maneira de fazer um balanço de sua própria vida e, assim, compreender o sujeito que veio a ser depois de adulto.

Já em Paula, uma narrativa de maior densidade, tal é a circunstância em que foi produzida, encontra-se a escritora Isabel Allende evocando sua história num quarto de hospital em que sua filha Paula se encontrava em coma irreversível. Nas linhas que escreve, ela redesenha sua vida. Acreditando que a força de suas palavras a aproximaria de sua filha mesmo durante o coma, Isabel transforma-se numa espécie de narradora de si mesma e retorna ao seu passado, falando desde seus ancestrais, sua infância, sua juventude, até o golpe militar vivido pelo Chile, na década de 1970, que viria a levar sua família ao exílio. A narradora aborda problemas de ordem social e também seus segredos mais íntimos, seus medos, suas alegrias, ela reconstrói sua história ao que sua memória lhe permite e parece acreditar no poder de suas palavras e na força de sua história de vida diante da fragilidade de Paula.

A escrita de si seria, pois, o espaço de materialização das histórias dos indivíduos e de seus grupos. E indivíduos dos mais comuns, com trajetórias também comuns, preenchidas por acontecimentos dos mais diversificados. Indivíduos que não precisam realizar um grande feito em nome de uma nação, mas que precisam driblar uma vida de acontecimentos em nome de sua própria sobrevivência. 
A valorização/aceitação das escritas de si revela que a sociedade moderna, talvez em consequência do sujeito cartesiano apontado por Foucault (2006) - aquele que volta o seu olhar para si -, abriu espaço para o indivíduo. Em outros termos, a modernidade fomenta a escrita de si a partir do momento em que valoriza o indivíduo em seu anonimato, em seu cotidiano não menos importante que o cotidiano dos ditos grandes homens.

\section{Escrita de si e memória}

Uma escrita de si seria, sumariamente, aquela em que o sujeito aborda a sua própria história como temática de seus escritos. Contudo, ao tomar-se no plano de uma narrativa, esse sujeito trará consigo, também, o espaço e em que se insere, bem como os grupos sociais aos quais pertence. Logo, uma escrita de si nunca será a história de um sujeito isolado, neutro. A exemplo das cartas trocadas entre Mário de Andrade e Carlos Drummond, Gomes defende que "[...] o diálogo entre os dois constitui uma oportunidade para se 'ler e sentir' o movimento modernista sob outros ângulos" (GOMES, 2004, p. 07). Desse modo, é possível considerar que a história de Hermilo em Margem das Lembranças é também a história da Revolução de 1930 e a narrativa de Allende, em Paula, é também parte da história da ditadura militar no Chile, o que significa dizer que as escritas de si são compostas de memórias coletivas, na medida em que esses sujeitos que se dizem recorrem à história de grupos sociais e de momentos históricos.

Ao recorrer à Revolução de 1930 para relatar alguns acontecimentos que viveu, Hermilo está fazendo da história um lugar de memória do sujeito que se narra. E aí ele dá conta de uma coletividade, inevitavelmente. Os seus amigos Luís Lopes, Miguel Pescador, Manoel Izidoro surgem como motivações para seu envolvimento com os acontecimentos políticos de então. Da mesma forma, a ditadura chilena surge no interior da narrativa de Allende abarcando uma coletividade da qual a autora se mune para escrever o relato de sua vida.

Dessa relação entre história e memória, cumpre pensar as diferenças apontadas por Chatier (2009, p. 21): primeiramente, teríamos "a que distingue o testemunho do documento"; em segundo, uma diferença que "opõe o imediatismo da reminiscência à construção da explanação histórica"; em terceiro, a diferença que "opõe reconhecimento do passado e representação do passado", caso da obra literária.

A "forma literária", em seus diversos gêneros, incluindo-se aí a narrativa, "[...] opõe uma resistência ao que ele designa como 'a pulsão referencial do relato histórico' [...]" (RICOEUR apud CHATIER, 2009, p. 23). Essa possibilidade de a história representar o passado é questionada devido ao fosso existente entre o passado representado e as "formas discursivas necessárias para sua representação", destaca Chatier (2009, p. 23), ao mesmo tempo em que questiona a certificação da "representação histórica do passado". A resposta é buscada no próprio Ricoeur. Primeiramente, há que se

Distinguir claramente e articular as três 'fases' da operação historiográfica: o estabelecimento da prova documental, a construção da explicação e a colocação em forma literária. A segunda resposta [...] remete à certeza da existência do passado tal como assegura o testemunho da memória. (CHATIER, 2009, p. 23) 
A memória, pois, tem uma dupla tarefa na escrita de si: ao mesmo tempo em que permite o acesso aos acontecimentos passados por meio do testemunho, ela solidifica o discurso histórico, seja no documento, seja na forma literária. Além do mais, a memória não surge do vazio isolado, ela se materializa no indivíduo que dela lança mão e, por sua vez, traz consigo a representação de uma coletividade. Vale frisar aqui a polifonia presente no Manifesto do Alerta, texto escrito por LL, amigo de Hermilo, às vésperas do estouro da Revolução, e distribuído por ambos, madrugada adentro, por debaixo das portas:

\begin{abstract}
Não pense em viver sossegadamente, sempre, sempre, mas pense que existem regimes políticos, fome e pessoas enlouquecidas pelo poder; pense que estamos vivendo num mundo ao mesmo tempo opaco e cruel; pense que os políticos têm uma mente única, propagando milhares de vocábulos vazios e gesticulando com milhões de gestos inúteis; pense que os oprimidos criaram uma palavra única: Liberdade; pense que estes trabalham para criar uma Religião do Homem contra a falsa religião deles; pense que nascemos numa estrutura sem base; pense que estamos transformando a Religião em algo bem mais violento; pense que os outros compuseram uma sinfonia abstrata de destrutiva; pense que eles construíram um sistema para desmiolar o homem. São necessários, portanto, uma, duas, três, quatro, mil revoluções. Cinco milhões de revoluções. Até que o homem volte a ser homem. (BORBA FILHO, 1993, p. 200)
\end{abstract}

As muitas vozes que aqui falam exemplificam através do discurso de protesto como a coletividade, ao mesmo tempo em que fala, é evocada a se posicionar frente ao panorama político vivenciado. O manifesto é uma espécie de incitação que vem da voz de um grupo que luta por mudanças de cunho social e político e se dirige ao povo: um "nós" discursando para todos. Além disso, sendo Margem das Lembranças uma escrita de si, este trecho permite inferir como o "eu" da narrativa se constrói a partir de tantos outros "eus".

Na comovente narrativa Paula, verifica-se a trajetória de Isabel Allende e de sua família contada sob o crivo de momentos muito dolorosos. Enquanto Paula morre aos poucos, sua mãe tenta Ihe dizer: "Escute, Paula, vou contar uma história para que você não se sinta perdida quando acordar" (ALLENDE, 2008, p. 09). Essa história, a sua, é contada com um intuito que a autora logo esclarece para a filha que já não pode ouvi-la: "Jogo-me nestas páginas, numa tentativa irracional de vencer meu terror, parece que, dando forma a esta devastação, poderei ajudar você e me ajudar, o meticuloso exercício da escrita pode ser a nossa salvação" (ALLENDE, 2008, p. 17).

A narradora, uma mãe em desespero, acredita que refazer a trajetória de suas vidas será uma maneira de amenizar seu sofrimento. Mas que efeito ou poder é esse dado a um escrito sobre si próprio? Aqui se pode pensar por dois vieses: o estatuto do sujeito que se narra e o estatuto da escrita de si, numa tentativa de compreender esse efeito provocado naquele que se diz.

Para Gomes (2004), a escrita de si "[...] assume a subjetividade de seu autor como dimensão integrante de sua linguagem, construindo sobre ela a sua verdade" (GOMES, 2004, p.14), ou seja, ao se dizer em primeira pessoa, o sujeito "busca um 'efeito de verdade"' por meio do qual intenciona revelar suas dimensões 'íntimas e profundas', conferindo, dessa forma, legitimidade ao seu texto. Já Sibília (2008), por seu turno, fala de um "efeito-sujeito", alcançado exatamente quando o sujeito se desprende da sua realidade e se transpõe para a esfera da narrativa, segundo ela "[...] uma ficção necessária, pois somos feitos desses relatos: eles são a memória que nos constitui enquanto sujeitos." Assim, Sibília está condicionando "a experiência de si" "à condição de narrador do sujeito", "este que viria a se constituir 
realmente ao se dizer através de uma narrativa em primeira pessoa" (SIBILIA, 2008, p. 31). Portanto, torna-se possível pensar a necessidade da narradora de Paula em "contar uma história". Allende estaria, possivelmente, buscando em suas memórias a consistência de que seu eu já não dispunha diante da quase morte de sua filha. É a linguagem que dá consistência, defende Sibília, logo, é nela que Allende percebe o espaço em que poderia, junto com sua filha, manter o estatuto de sujeito de ambas. Somente ali, em sua narrativa, elas poderiam manter-se juntas por mais tempo.

Uma dicotomia interessante, apresentada por Gomes (2004), diz respeito ao "estatuto da escrita de si", em que se questiona a relação entre o texto e o "seu 'autor"'. De um lado, defende-se que o texto "é uma 'representação' de seu autor"; do outro, defende-se que "[...] o autor é uma 'invenção' do próprio texto, sendo sua sinceridade/subjetividade um produto da narrativa que elabora" (GOMES, 2004, p. 1516). O fato é que essa questão se coloca como um "falso paradoxo", mas que ajuda a entender a dinâmica da escrita de si, pois

[...] começa a ganhar terreno a posição que considera que o indivíduo/autor não é nem 'anterior' ao texto, uma 'essência' refletida por um 'objeto' de sua vontade, nem 'posterior' ao texto, um efeito, uma invenção do discurso que constrói. Defende-se que a escrita de si é, ao mesmo tempo, constitutiva da identidade de seu autor e do texto, que se criam, simultaneamente, através dessa modalidade de 'produção do eu'. (GOMES, 2004, p. 16)

Conclui-se, pois, que é dessa imbricação entre autor e texto, presente na escrita de si, que esse tipo de registro deixará transparecer elementos constitutivos do sujeito que o produz, bem como de sua cultura e da cultura do grupo onde vive. Entretanto, a abordagem acima exposta converge para a ideia de que a escrita de si tem "editores" em lugar de autores. Para Gomes, seguindo o raciocínio acima, a escrita de si teria, neste caso, a tarefa de "[...] rearranjar e significar o trajeto de uma vida no suporte do texto, criando-se, através dele, um autor e uma narrativa" (GOMES, 2004, p. 16).

Ao refletir sobre a noção de verdade e sociedade a partir da concepção grega de Alétheia, Marcel Detienne (1988, p. 13) nota que "Através de sua memória, o poeta tem acesso direto, mediante uma visão pessoal, aos acontecimentos que evoca; tem o privilégio de entrar em contato com o mundo. Sua memória permite-Ihe 'decifrar o invisível'". É esse poder que dá ao sujeito da escrita de si a liberdade de se expressar subjetivamente a partir de suas percepções, trazendo à superfície da escrita a sua verdade que, exatamente por ser fruto de suas percepções, se torna algo um tanto incontestável, porque também não deixa de se identificar com o "Ser do homem" representado no texto, para o qual o poeta concede uma memória, visto que já desde a época arcaica "Em suas palavras os homens se reconhecem" (DETIENNE, 1998, p. 20-23).

Portanto, tanto Hermilo como Allende estariam não apenas dando consistência aos seus eus em suas respectivas narrativas, como também de alguma forma estariam dando mais consistência às identidades daqueles a quem inevitavelmente evocam ao contar suas histórias, mediante sua linguagem. Como afirma Sibilia (2008),

A linguagem não só ajuda a organizar o tumultuado fluir da sua própria experiência e a dar sentido ao mundo, mas também estabiliza o espaço e ordena o tempo, em diálogo constante com a multidão de outras vozes que também nos modelam, coloreiam e recheiam. (SIBILIA, 2008, p. 31) 
A linguagem da escrita de si, pois, mais que dizer o sujeito que se narra, dá-lhe a possibilidade de por ordem em sua vida e de evocar vozes a fim de reorganizar sua trajetória no plano da narrativa e, assim, tomar para si a consistência desejável, mas não atingida em tempo: "[...] a experiência vital de cada sujeito é um relato que só pode ser pensado e estruturado como tal se for dissecado na linguagem" (SIBILIA, 2008, p. 32).

\section{Memória individual e memória coletiva na escrita de si}

Essa evocação de vozes, presente na escrita de si, converge para uma discussão há algum tempo iniciada pelo francês Halbwachs, defensor de que em cada pessoa coexistem dois seres: o "ser sensível", que pode ser considerado uma "espécie de testemunha que vem depor sobre o que viu", e um outro eu, que não viu, mas que pode ter visto. Ele completa: "Se o que vemos hoje toma lugar no quadro de referências de nossas lembranças antigas, inversamente essas lembranças se adaptam ao conjunto de nossas percepções do presente" (HALBWACHS, 2006, p. 29). É como se essas lembranças funcionassem como espécies de testemunhos numa situação de reconstrução de um passado cujo valor de verdade seria atestado mediante certa convergência entre esses testemunhos. Em outros termos, para Halbwachs, as lembranças terão maior validade se baseadas não apenas no testemunho daquele que pensa um acontecimento passado, mas nas lembranças de outros. Assim, a presença de outros sujeitos nas escritas de si pode ser tomada como reforços àquilo que o narrador aponta em seu relato como um acontecimento de sua vida. Daí porque o narrador hermiliano recorre às pessoas com as quais partilhou suas experiências para contar sua história - esses outros são, na verdade, testemunhas de sua vida, eles dão veracidade ao seu dizer-se:

\footnotetext{
Eu estou na balança. Todos os meus atos estão num dos pratos da balança. De um lado, os demais: muitos deles sou eu, metamorfoseado, irreconhecível, adulterado; do outro, eu mesmo, integral, de carne, as pernas penduradas no vazio. [...] Este sou eu, tanto no passado - vida morta - como no presente que se estende pelos dias e pelas noites sem nada com o futuro inexistente, apenas inventado pela imaginação e com certeza diferente do que espero. Merda para o futuro! Teço neste papel. Um passado real, às vezes, e, outras, puramente imaginado na esperança de que no fim Deus confunda o que vivi e o que inventei e me dê um saldo favorável para uma modesta pensão no purgatório. (BORBA FILHO, 1993, p. 15)
}

Essa possibilidade de recorrer aos "demais" abre espaço para o narrador fazer uso de uma memória coletiva em nome de sua própria memória. Mediante a memória, ele pode selecionar os recortes que julga relevantes em nome da reconstrução de sua história no plano da narrativa: "O registro da memória é sem dúvida mais seletivo e opera o Double bind entre lembrança e esquecimento [...]" (SELIGMANN-SILVA, 2003, p. 62). Assim, a memória flutua entre a lembrança e o esquecimento e, no caso de ela pender mais para este último, "os outros" podem servir de "fio de Ariadne" para aquele que se diz chegar mais próximo daquilo que viveu, como atesta Halbwachs ao dizer que "Nossas lembranças permanecem coletivas e nos são lembradas por outros [...]"(HALBWACHS, 2006, p.30).

Desse modo, encontramos na narrativa emocionante de Isabel Allende a memória de sua família e também do povo chileno, especialmente aquele que viveu o Golpe Militar de 1973, quando o presidente 
Salvador Allende foi encurralado em seu gabinete afirmando "de La Moneda ninguém me tirará vivo", enquanto os militares dominavam o país:

\begin{abstract}
A má notícia logo se espalhou, e ministros secretários, funcionários, médicos de confiança, alguns jornalistas e amigos chegaram ao palácio; era uma pequena multidão que dava voltas pelos salões sem saber o que fazer, improvisando táticas de combate [...] Os mais angustiados opinavam que chegara a hora de convocar o povo para uma manifestação maciça em defesa do governo, porém, Allende calculou que haveria milhares de mortos. (ALLENDE, 2008, p. 256)
\end{abstract}

Essa "pequena multidão" é que permite à narradora reconstituir parte do passado político do Chile. Ao trazer a sua história de vida para um plano narrativo, ela inevitavelmente abarca muitos outros personagens e estes, por sua vez, seriam tomados como possíveis testemunhas para validar seu discurso, numa espécie de confluência das memórias de ambos - "Para que a nossa memória de aproveite da memória dos outros, não basta que estes nos apresentem seus testemunhos", diz Halbwachs (2006, p. 39). Para ele, é preciso que existam pontos em comum entre a memória de um sujeito e a memória do grupo por ele evocado, o que significa que a memória dos outros evocada por Allende, a respeito tanto de sua família quanto de seu país, só ganha validade porque essa memória que é coletiva também lhe é individual. Em outras palavras, Allende também viveu os difíceis momentos políticos do Chile e aquilo que ela extrai da memória dos outros não lhe é estranho.

\begin{abstract}
Não basta reconstituir pedaço a pedaço a imagem de um acontecimento passado para ter uma lembrança. É preciso que esta reconstrução funcione a partir de dados ou de noções comuns que estejam em nosso espírito e também no dos outros, porque elas estão sempre passando destes para aquele e vice-versa, o que será possível somente se tiverem feito parte e continuarem fazendo parte de uma mesma sociedade, de um mesmo grupo. (HALBWACHS, 2006, p. 39)
\end{abstract}

Em outros termos, a memória é algo que ganha consistência apenas quando é partilhável. Ela ganha sentido quando faz parte de um grupo, quando é comum aos indivíduos de um grupo. Só assim ela poderá ser tomada com mais validade como uma forma de representação do passado.

Vale aqui retomar Seligmann-Silva quando ele aponta que conceitos iluministas como o de linearidade da história foram deixados de lado enquanto "observou-se mais e mais a ascensão do registro da memória - que é fragmentário, calcado na experiência individual e da comunidade [...] e não tem como meta a tradução integral do passado" (SELIGMANN-SILVA, 2002, p. 65). É justamente por dar espaço para a coletividade que o discurso memorialista é fragmentado. Nele todos falam. Cada um tem algo a apresentar quando se trata de reconstituir um passado. Parece não haver individualismo em assuntos de memória. Embora para cada sujeito os acontecimentos vivenciados tenham significados diferentes, o que leva cada um a elaborar a sua memória sobre os fatos, essas percepções individuais é que irão, juntas, construir o significado coletivo, num entrecruzamento que resulta na história não de indivíduos isolados, mas do grupo a que pertencem. 


\section{A literatura de testemunho}

Se a memória é fragmentária, pode-se dizer o mesmo em relação ao testemunho. "Nele, de um modo característico para a nossa pós-modernidade, o universal reside no mais fragmentário" (SELIGMANN-SILVA, 2003, p. 80). E, como exemplo, o autor fala da história da Shoah, contada por milhares de vítimas sobreviventes a este evento.

Quanto à literatura de testemunho, Seligmann-Silva aponta que se trata de um novo gênero literário, característico da Hispano-América que passa da função testemunhal da literatura, caso da Alemanha, França e EUA a respeito da Shoah, para a conceituação desse novo gênero que, a par das questões político-partidárias na América Latina, é tomado como o mais adequado para dar voz aos "revolucionários". No entanto, "[...] não se deve confundir o testemunho [...] com a literatura de testemunho propriamente dita. Esta, no entanto, existe apenas no contexto da contra-história, da denúncia e da busca pela justiça" (SELIGMANN-SILVA, 2005, p. 88). Assim, Hermilo Borba Filho escreveria uma quadrilogia composta por quatro romances na década de 1960 e 1970, contexto da ditadura militar, para mostrar que os estragos provocados pela política brasileira já compunham uma longa história. Em Margem das Lembranças, o ponto alto de sua narrativa é o estouro da Revolução de 1930, que Ihe rendeu a prisão, muitas torturas e um aprendizado que talvez o tenham tornado um homem diferente daquele que ele encontra nas páginas de sua vida ao narrar sua própria história lá de longe, de um futuro que ele não fazia ideia de como seria.

Na literatura de testemunho, "[...] destaca-se o ser 'coletivo' da testemunha" (ACHUGAR apud SELIGMANN-SILVA, 2005, p. 89), numa espécie de simbiose entre a história e a memória. Eis, de acordo com Seligmann, o cerne da literatura de testemunho: do imbricamento entre história e memória é que ela surge. Logo, ao narrar suas memórias num plano narrativo e trazer para esta esfera o cenário político de um Chile golpeado na década de 1970, Allende está produzindo uma literatura de testemunho na medida em que, enquanto se retrata em seu texto, ela também apresenta ao leitor parte da história de seu país. Suas palavras parecem uma tentativa de esclarecer pontos obscuros do golpe sofrido pelo presidente Salvador Allende: tentando mostrar a devassidão que assolou sua família e a de tantos outros cidadãos chilenos, a narradora conta:

\footnotetext{
A casa do presidente foi tomada de assalto, depois de ter sido bombardeada e até a roupa da família foi saqueada. A vizinhança e os soldados levaram como recordação os objetos pessoais, os documentos mais íntimos e as obras de arte que os Allende haviam colecionado ao longo da vida. Nas comunidades operárias, a repressão foi implacável, houve execuções sumárias no país inteiro, um sem-número de prisioneiros, desaparecidos e torturados, não havia onde esconder tantos perseguidos nem como alimentar milhares de famílias sem trabalho. (ALLDENDE, 2008, p. 258)
}

A história do povo chileno nas páginas narradas por uma escritora chilena. Possivelmente uma forma de fazer justiça através de uma memória narrativa que ecoa a voz não apenas da narradora, mas de uma legião de afetados pela ditadura. Na literatura de testemunho, diz Seligmann-Silva, "[...] há um sentido de necessidade de se fazer justiça, de se dar conta da exemplaridade do 'herói' e de se conquistar uma voz para o subalterno" (SELIGMANN-SILVA, 2005, p. 89). Daí a polifonia presente na literatura de testemunho, como na escrita de si: diversas vozes são evocadas para dar voz àquele que fala e que, por 
seu turno, como dito, dar voz a um subalterno. Talvez Isabel Allende esteja dando voz a Salvador Allende, em sua narrativa. Talvez Hermilo Borba Filho, numa tarefa dupla, esteja dando voz aos oprimidos pela Revolução de 1930 e, também, àqueles que sofreram a ditadura de 1960, no Brasil, uma vez que ele fala, em Margem das Lembranças, de um acontecimento político de sua juventude, mas no momento em que o seu país vive outros conflitos - a ditadura militar de 1960.

Em suma, na literatura de testemunho, tem-se um sujeito narrador que estabelece uma relação com o passado cuja interação é mediada pela memória, a dele mesmo e a dos outros que também participaram dos acontecimentos desse passado. Sendo que se deve considerar o caráter subjetivo da literatura de testemunho, visto que esta advém da percepção daquele que narra. O testemunho é reconstituído com o auxílio da memória e esta é uma "modalidade mais emocional", afirma SeligmannSilva (2003, p. 79). Além disso, "A tarefa de lembrar a tragédia, [...] envolve ainda o enfrentamento, por parte do narrador, do sofrimento experimentado [...]" (SELIGMANN-SILVA, 2003, p. 364). Ao testemunhar, o narrador revive porque recria os fatos passados, no presente, embora no plano ficcional da narrativa.

\section{Algumas considerações}

As escritas de si configuram-se em uma modalidade por meio da qual o sujeito moderno passou a dizer-se. Nelas a presença de um narrador que busca a reconstituição de seu passado, ou de parte dele, aparentemente com o intuito de compreender-se a si mesmo. $\mathrm{O}$ ambiente da escrita de si é aquele em que o narrador esteve outrora - o seu passado. É de lá que ele traz ao presente acontecimentos que mudaram ou transformaram o curso de suas vidas. Mediante a escrita de si, o sujeito que se narra tem a possibilidade de analisar de fora eventos que the aconteceram, o que the dá a capacidade de pensar criticamente sua postura diante de tais fatos. Tanto em Margem das Lembranças quanto em Paula, os narradores rememoram suas vidas como se numa possível tentativa de compreender o rumo que tomaram até o presente em que estão a dizer-se.

A memória apresenta-se como uma indispensável aliada das escritas de si. É através das lembranças que o sujeito tem acesso ao seu passado, seja aos acontecimentos mais corriqueiros como as brincadeiras de infância de Allende e as primeiras experiências sexuais do jovem Hermilo, seja aos grandes traumas como o golpe militar do Chile ou a Revolução de 1930 no Brasil. De qualquer forma, a memória aparece como elemento norteador para o sujeito da escrita de si.

A literatura de testemunho, por sua vez, tem a tarefa de materializar no plano discursivo aquilo de que a memória dá conta e que será levado ao plano narrativo. A partir dela, o sujeito reconstrói fatos passados, denuncia o que foi ocultado, reafirma o que foi vivenciado, dá voz àqueles que não puderam se manifestar. A literatura de testemunho dá ao sujeito a possibilidade de reunir fragmentos do passado e, assim, ressignificar a história de vida dos sujeitos inseridos nesses fragmentos, nessas histórias.

As narrativas em primeira pessoa, a memória e o testemunho/literatura de testemunho podem ser tomados, pois, como uma tríplice possibilidade mediante a qual o sujeito pode dizer-se. Juntos, esses elementos podem dar ao narrador a possibilidade de, no plano ficcional, reorganizar a trajetória de sua 
vida. O entrelaçamento desse tríplice pode dar ao sujeito a possibilidade de retornar ao passado e, consequentemente, compreender melhor o seu presente.

\section{Referências Bibliográficas:}

ALLENDE, Isabel. Paula. Trad. Irene Moutinho. 2 ed. Rio de Janeiro: BestBolso, 2008.

BORBA FILHO, Hermilo. Margem das lembranças. 2. ed. Porto Alegre: Mercado Aberto, 1993.

CHARTIER, Roger. A história ou a leitura do tempo. Trad. Cristina Antunes. Belo Horizonte: Autêntica, 2009.

DETIENNE, Marcel. Os mestres da verdade na Grécia arcaica. Rio de Janeiro: Jorge Zahar, 1988.

FOUCAULT, Michel. A hermenêutica do sujeito. Trad. Márcio Alves da Fonseca, Salma Tannus Muchail. 2. ed. São Paulo: Martins Fontes, 2006.

HALWACHS, Maurice. A memória coletiva. Trad. Beatriz Sidou. São Paulo: Centauro, 2006.

GOMES, Angela de Castro (org.). Escrita de si, escrita da história. Rio de Janeiro: FGV, 2004.

SELIGMANN-SILVA, Márcio. Reflexões sobre a Memória, História e o esquecimento. In: memória, literatura: o Testemunho na era das catástrofes. Campinas, São Paulo: UNICAMP, 2003. História, O local da diferença: ensaios sobre memória, arte, literatura e tradução. São Paulo: 34, 2005.

SILIBIA, Paula. O show do eu: a intimidade como espetáculo. Rio de Janeiro: Nova Fronteira, 2008. 